\title{
FIXED POINT THEOREMS FOR TWO PAIRS OF MAPPINGS SATISFYING A NEW TYPE OF COMMON LIMIT RANGE PROPERTY IN $G_{p}$ METRIC SPACES
}

\author{
Valeriu Popa, Alina-Mihaela Patriciu
}

\begin{abstract}
The purpose of this paper is to prove a general fixed point theorem for mappings involving almost altering distances and satisfying a new type of common limit range property in $G_{p}$ metric spaces. In the last part of the paper, some fixed point results for mappings satisfying contractive conditions of integral type and for $\varphi$-contractive mappings are obtained.
\end{abstract}

\section{Introduction}

Let $(X, d)$ be a metric space and $S, T$ be self mappings of $X$. In [19], Jungck defined $S$ and $T$ to be compatible if

$$
\lim _{n \rightarrow \infty} d\left(S T x_{n}, T S x_{n}\right)=0
$$

whenever $\left\{x_{n}\right\}$ is a sequence in $X$ such that

$$
\lim _{n \rightarrow \infty} S x_{n}=\lim _{n \rightarrow \infty} T x_{n}=t
$$

for some $t \in X$.

Received: 24.11.2016. Accepted: 24.02.2018. Published online: 14.05.2018.

(2010) Mathematics Subject Classification: 54H25, 47H10.

Key words and phrases: fixed point, almost altering distance, common limit range property, $G_{p}$-metric spaces, implicit relation. 
This concept has been frequently used to prove existence theorems in fixed point theory.

Let $f, g$ be self maps of a nonempty set $X$. A point $x \in X$ is a coincidence point of $f$ and $g$ if $w=f x=g x$; $w$ is then said to be a point of coincidence of $f$ and $g$. The set of all coincidence points of $f$ and $g$ is denoted by $\mathcal{C}(f, g)$.

In 1994, Pant ([35]) introduced the notion of pointwise $R$-weakly commuting mappings. It is proved in [36] that the pointwise $R$-weakly commutativity is equivalent to commutativity in coincidence points.

In [20], Jungck introduced the concept of weakly compatible mappings.

Definition $1.1([20])$. Let $X$ be a nonempty set and $f, g$ be self mappings on $X$. Functions $f$ and $g$ are weakly compatible if $f g u=g f u$ for all $u \in \mathcal{C}(f, g)$.

Hence, $f$ and $g$ are weakly compatible if and only if $f$ and $g$ are pointwise $R$-weakly commuting.

The study of common fixed points for noncompatible mappings is also interesting, the work in this regard was initiated by Pant [37]-[39].

Aamri and El Moutawakil introduced a generalization of noncompatible mappings in [1].

Definition $1.2([1])$. Let $S$ and $T$ be two self mappings of a metric space $(X, d)$. We say that $S$ and $T$ satisfy $(E . A)$-property if there exists a sequence $\left\{x_{n}\right\}$ in $X$ such that

$$
\lim _{n \rightarrow \infty} S x_{n}=\lim _{n \rightarrow \infty} T x_{n}=t
$$

for some $t \in X$.

REMARK 1.1. It is clear that two self mappings $S$ and $T$ of a metric space $(X, d)$ are noncompatible if there exists $\left\{x_{n}\right\}$ in $X$ such that $\lim _{n \rightarrow \infty} S x_{n}=$ $\lim _{n \rightarrow \infty} T x_{n}=t$ for some $t \in X$ but $\lim _{n \rightarrow \infty} d\left(S T x_{n}, T S x_{n}\right)$ is nonzero or does not exist. Therefore, two noncompatible self mappings of a metric space $(X, d)$ satisfy $(E . A)$-property.

It is known from [41, 43 that the notions of weakly compatible mappings and mappings satisfying (E.A)-property are independent.

In 2005, Liu et al. ([26]) defined the notion of common (E.A)-property.

Definition 1.3 ([26]). Two pairs $(A, S)$ and $(B, T)$ of self mappings on a metric space $(X, d)$ are said to satisfy common $(E . A)$-property if there exist two sequences $\left\{x_{n}\right\}$ and $\left\{y_{n}\right\}$ in $X$ such that

$$
\lim _{n \rightarrow \infty} A x_{n}=\lim _{n \rightarrow \infty} S x_{n}=\lim _{n \rightarrow \infty} B y_{n}=\lim _{n \rightarrow \infty} T y_{n}=t
$$

for some $t \in X$. 
There exists a vast literature concerning the study of fixed points for mappings satisfying (E.A)-property.

In 2011, Sintunavarat and Kumam ([58]) introduced the notion of common limit range property.

Definition $1.4([58])$. A pair $(A, S)$ of self mappings of a metric space $(X, d)$ is said to satisfy the common limit range property with respect to $S$ (shortly $C L R_{(S)}$-property), if there exists a sequence $\left\{x_{n}\right\}$ in $X$ such that $\lim _{n \rightarrow \infty} A x_{n}=\lim _{n \rightarrow \infty} S x_{n}=t$ for some $t \in S(X)$.

Thus, we can infer that a pair $(A, S)$ satisfying $(E . A)$-property along with the closedness of the subspace $S(X)$ always has $C L R_{(S)}$-property with respect to $S$.

Recently, Imdad et al. ([16]) introduced the notion of common limit range property for two pairs of self mappings.

Definition $1.5([17])$. Two pairs $(A, S)$ and $(B, T)$ of self mappings in a metric space $(X, d)$ are said to satisfy common limit range property with respect to $S$ and $T$ (shortly $C L R_{(S, T)}$-property), if there exist two sequences $\left\{x_{n}\right\}$ and $\left\{y_{n}\right\}$ in $X$ such that $\lim _{n \rightarrow \infty} A x_{n}=\lim _{n \rightarrow \infty} S x_{n}=\lim _{n \rightarrow \infty} B y_{n}=$ $\lim _{n \rightarrow \infty} T y_{n}=t$ for some $t \in S(X) \cap T(X)$.

Some fixed point results for pairs of mappings with $C L R_{(S)}$ and $C L R_{(S, T)^{-}}$ -property are obtained in [15, 17, 18, 23] and in other papers.

Now we introduce a new type of common limit range property.

Definition 1.6 ([45]). Let $A, S$ and $T$ be self mappings of a metric space $(X, d)$. The pair $(A, S)$ is said to satisfy limit range property with respect to $T$ (shortly $C L R_{(A, S) T}$-property), if there exists a sequence $\left\{x_{n}\right\}$ in $X$ such that

$$
\lim _{n \rightarrow \infty} A x_{n}=\lim _{n \rightarrow \infty} S x_{n}=t
$$

for some $t \in S(X) \cap T(X)$.

EXAMPLE 1.1. Let $\mathbb{R}_{+}$be the metric space with the usual metric, $A x=$ $\frac{x^{2}+1}{2}, S x=\frac{x+1}{2}, T x=x+\frac{1}{4}$. Then $S(X)=\left[\frac{1}{2}, \infty\right), T(X)=\left[\frac{1}{4}, \infty\right), S(X) \cap$ $T(X)=\left[\frac{1}{2}, \infty\right)$. Let $\left\{x_{n}\right\}$ be a sequence in $X$ such that $\lim _{n \rightarrow \infty} x_{n}=0$. Then $\lim _{n \rightarrow \infty} A x_{n}=\lim _{n \rightarrow \infty} S x_{n}=\frac{1}{2}=z$ and $z \in S(X) \cap T(X)$.

REMARK 1.2. Let $A, B, S$ and $T$ satisfy the common limit range property with respect to $S$ and $T$. Then $(A, S)$ satisfy the common limit range property with respect to $T$. The converse is not true. To see this, consider the metric space and the functions $A, S, T$ defined in Example 1.1 and put $B x=x^{2}+\frac{1}{4}$. 
Suppose that $(A, S)$ and $(B, T)$ have $C L R_{(S, T)}$-property. Then there exist sequences $\left\{x_{n}\right\},\left\{y_{n}\right\}$ and $t \geq \frac{1}{2}$ such that $\lim _{n \rightarrow \infty} A x_{n}=\lim _{n \rightarrow \infty} S x_{n}=$ $\lim _{n \rightarrow \infty} B y_{n}=\lim _{n \rightarrow \infty} T y_{n}=t$. Since $\lim _{n \rightarrow \infty} B y_{n}=\lim _{n \rightarrow \infty} T y_{n}=t \geq \frac{1}{2}$, then $y_{n} \rightarrow 1$ and thus, $t=\frac{5}{4}$. But $\lim _{n \rightarrow \infty} A x_{n}=\lim _{n \rightarrow \infty} S x_{n}$ only if $x_{n} \rightarrow 0$ or $x_{n} \rightarrow 1$. In both cases $\lim _{n \rightarrow \infty} A x_{n} \neq \frac{5}{4}$, a contradiction. Hence, the pairs $(A, S)$ and $(B, T)$ do not satisfy $C L R_{(S, T)}$-property.

Definition $1.7([24])$. An altering distance is a mapping $\psi:[0, \infty) \rightarrow$ $[0, \infty)$ such that

$\left(\psi_{1}\right) \psi$ is increasing and continuous,

$\left(\psi_{2}\right) \psi(t)=0$ if and only if $t=0$.

Fixed point problems involving altering distances have been studied in [47, 55, 56] and in other papers.

Definition 1.8 ([51]). A function $\psi:[0, \infty) \rightarrow[0, \infty)$ is an almost altering distance if

$\left(\psi_{1}\right) \psi$ is continuous,

$\left(\psi_{2}\right) \psi(t)=0$ if and only if $t=0$.

EXAMPLE 1.2. Every altering distance is an almost altering distance, but the converse is not true as we can see in the following example of function:

$$
\psi(t)= \begin{cases}t, & t \in[0,1], \\ \frac{1}{t}, & t \in(1, \infty) .\end{cases}
$$

\section{Preliminaries}

In [11, 12], Dhage introduced a new class of generalized metric spaces, named $D$-metric spaces.

Mustafa and Sims $([32,33])$ proved that most of the claims concerning the fundamental topological structures on $D$-metric spaces are incorrect and introduced an appropriate notion of generalized metric space, named $G$-metric space. In fact, Mustafa, Sims and other authors studied many fixed point results for self mappings under certain conditions (see [29, 30, 31, 32, 34, 57] and other papers).

Definition 2.1 ([33]). Let $X$ be a nonempty set and let $G: X^{3} \rightarrow \mathbb{R}_{+}$be a function satisfying the following properties: 
$\left(G_{1}\right) G(x, y, z)=0$ if $x=y=z$,

$\left(G_{2}\right) 0<G(x, x, y)$ for all $x, y \in X$ with $x \neq y$,

$\left(G_{3}\right) G(x, y, y) \leq G(x, y, z)$ for all $x, y, z \in X$ with $z \neq y$,

$\left(G_{4}\right) G(x, y, z)=G(y, z, x)=\ldots$ (symmetry in all three variables),

$\left(G_{5}\right) G(x, y, z) \leq G(x, a, a)+G(a, y, z)$ for all $x, y, z, a \in X$ (triangle inequality).

The function $G$ is called a $G$-metric on $X$ and $(X, G)$ is called a $G$-metric space.

Note that if $G(x, y, z)=0$ then $x=y=z$.

REMARK 2.1. Let $(X, G)$ be a $G$-metric space. If $y=z$, then by [45, Lemma 5.1], $G(x, y, y)$, is a quasi-metric on $X$. Hence, $(X, Q)$, where $Q(x, y)=$ $G(x, y, y)$, is a quasi-metric space and since every metric space is a particular case of a quasi-metric space, it follows that the notion of $G$-metric space is a generalization of metric space.

In 1994, Matthews ([28]) introduced the concept of partial metric spaces as a part of the study of denotional semantics of dataflow networks and proved the Banach contraction principle in such spaces.

Many authors studied some fixed points for mappings satisfying contractive conditions in partial metric spaces.

Quite recently, in [4, 9, 10, 21, 22, some fixed point theorems under various contractive conditions in partial metric spaces have been proved.

Definition $2.2([28])$. Let $X$ be a nonempty set. A function $p: X \times X \rightarrow$ $\mathbb{R}_{+}$is said to be a partial metric on $X$ if, for all $x, y, z \in X$ :

$\left(P_{1}\right) p(x, x)=p(y, y)=p(x, y)$ if and only if $x=y$,

$\left(P_{2}\right) p(x, x) \leq p(x, y)$,

$\left(P_{3}\right) p(x, y)=p(y, x)$,

$\left(P_{4}\right) p(x, z) \leq p(x, y)+p(y, z)-p(y, y)$.

The pair $(X, p)$ is called a partial metric space.

REMARK 2.2. Obviously, every metric space is a partial metric space.

Quite recently, Ahmadi Zand and Dehghan Nezhad ([3]) introduced a generalization of a $G$-metric space and a partial metric space, named $G_{p}$-metric space. Some results on fixed points in $G_{p}$-metric space have been obtained, e.g., in [5]- 7], 40, 52, 53].

Definition $2.3([3,40])$. Let $X$ be a nonempty set. A function $G_{p}: X^{3} \rightarrow$ $\mathbb{R}_{+}$is called a $G_{p}$-metric on $X$ if the following conditions are satisfied: $\left(G P_{1}\right) x=y=z$ if $G_{p}(x, y, z)=G_{p}(x, x, x)=G_{p}(y, y, y)=G_{p}(z, z, z)$, 
$\left(G P_{2}\right) 0 \leq G_{p}(x, x, x) \leq G_{p}(x, x, y) \leq G_{p}(x, y, z)$ for all $x, y, z \in X$ with $y \neq z$

$\left(G P_{3}\right) G_{p}(x, y, z)=G_{p}(y, z, x)=\ldots$ (symmetry in all three variables),

$\left(G P_{4}\right) G_{p}(x, y, z) \leq G_{p}(x, a, a)+G_{p}(a, y, z)-G_{p}(a, a, a)$ for all $x, y, z, a \in X$.

The pair $\left(X, G_{p}\right)$ is called a $G_{p}$-metric space.

Lemma 2.1 ([3]). Let $G_{p}$ be a $G_{p}$-metric on a nonempty set $X$. Then $G_{p}(x, y, y) \leq 2 G_{p}(x, x, y)-G_{p}(x, x, x)$.

Lemma $2.2([5])$. Let $\left(X, G_{p}\right)$ be a $G_{p}$-metric space. Then:

1) if $G_{p}(x, y, z)=0$ then $x=y=z$,

2) if $x \neq y$ then $G_{p}(x, y, y)>0$.

Definition $2.4([3])$. Let $\left(X, G_{p}\right)$ be a $G_{p}$-metric space and let $\left\{x_{n}\right\}$ be a sequence of points in $X$. A point $x \in X$ is said to be the limit of the sequence $\left\{x_{n}\right\}$, denoted by $x_{n} \rightarrow x$, if $\lim _{n, m \rightarrow \infty} G_{p}\left(x, x_{n}, x_{m}\right)=G_{p}(x, x, x)$. Then the sequence $\left\{x_{n}\right\}$ is called $G_{p}$-convergent to $x$.

Lemma $2.3([3])$. Let $\left(X, G_{p}\right)$ be a $G_{p}$-metric space. Then, for any $\left\{x_{n}\right\} \subset$ $X$ and $x \in X$, the following properties are equivalent:

a) $\left\{x_{n}\right\}$ is $G_{p}$-convergent to $x$,

b) $G_{p}\left(x_{n}, x_{n}, x\right) \rightarrow G_{p}(x, x, x)$ as $n \rightarrow \infty$,

c) $G_{p}\left(x_{n}, x, x\right) \rightarrow G_{p}(x, x, x)$ as $n \rightarrow \infty$.

Lemma $2.4([40])$. If $x_{n} \rightarrow x$ in a $G_{p}$-metric space $\left(X, G_{p}\right)$ and $G_{p}(x, x, x)=$ 0 , then for every $y \in Y$

1) $\lim _{n \rightarrow \infty} G_{p}\left(x_{n}, y, y\right)=G_{p}(x, y, y)$,

2) $\lim _{n \rightarrow \infty} G_{p}\left(x_{n}, x_{n}, y\right)=G_{p}(x, x, y)$.

Definition 2.5 (45]). Let $A, S$ and $T$ be self mappings of a $G_{p}$-metric space $\left(X, G_{p}\right)$. Then the pair $(A, S)$ is said to satisfy the common limit range property with respect to $T$ (shortly $C L R_{(A, S) T}$-property), if there exists a sequence $\left\{x_{n}\right\}$ in $X$ such that

$$
\lim _{n \rightarrow \infty} A x_{n}=\lim _{n \rightarrow \infty} S x_{n}=z
$$

for some $z \in X$ with $G_{p}(z, z, z)=0$ and $z \in S(X) \cap T(X)$. 


\section{Implicit relations}

Several classical fixed point theorems and common fixed point theorems have been unified considering a general condition by an implicit function in [43. 44.

A new type of implicit relation has been introduced in [4].

Some fixed point theorems for mappings satisfying an implicit relation in $G$-metric spaces have been proved in [48]-[51].

Recently, fixed point results for mappings satisfying an implicit relation in partial metric spaces have been obtained in [13, 14, 59].

Quite recently, some fixed point results for mappings satisfying implicit relations in $G_{p}$-metric spaces have been obtained in [52, 53].

Definition $3.1([4])$. Let $\mathcal{F}_{G_{p}}$ be the set of all real continuous functions $F: \mathbb{R}_{+}^{6} \rightarrow \mathbb{R}$ satisfying the conditions:

$\left(F_{1}\right) F(t, 0, t, 0,0, t)>0, \forall t>0$,

$\left(F_{2}\right) F(t, 0,0, t, t, 0)>0, \forall t>0$

$\left(F_{3}\right) F(t, t, 0,0, t, t)>0, \forall t>0$.

EXAMPLE 3.1. $F\left(t_{1}, \ldots, t_{6}\right)=t_{1}-a t_{2}-b t_{3}-c t_{4}-d t_{5}-e t_{6}$, where $a, b, c, d, e \in \mathbb{R}$ and $\max \{b+e, c+d, a+d+e\}<1$.

EXAMPLE 3.2. $F\left(t_{1}, \ldots, t_{6}\right)=t_{1}-k \max \left\{t_{2}, t_{3}, \ldots, t_{6}\right\}$, where $k \in[0,1)$.

EXAMPLE 3.3. $F\left(t_{1}, \ldots, t_{6}\right)=t_{1}-k \max \left\{t_{2}, t_{3}, t_{4}, \frac{t_{5}+t_{6}}{2}\right\}$, where $k \in$ $[0,1)$.

EXAMPLE 3.4. $F\left(t_{1}, \ldots, t_{6}\right)=t_{1}-k \max \left\{t_{2}, \frac{t_{3}+t_{4}}{2}, \frac{t_{5}+t_{6}}{2}\right\}$, where $k \in$ $[0,1)$.

EXAMPLE 3.5. $F\left(t_{1}, \ldots, t_{6}\right)=t_{1}-a t_{2}-b \max \left\{t_{3}, t_{4}\right\}-c \max \left\{t_{2}, t_{5}, t_{6}\right\}$, where $a, b, c \in \mathbb{R}$ and $\max \{a+c, b+c\}<1$.

EXAMPLE 3.6. $F\left(t_{1}, \ldots, t_{6}\right)=t_{1}-\max \left\{c t_{2}, c t_{3}, c t_{4}, a t_{5}+b t_{6}\right\}$, where $a, b, c \in \mathbb{R}$ and $\max \{a, b, c, a+b\}<1$.

ExAMPLE 3.7. $F\left(t_{1}, \ldots, t_{6}\right)=t_{1}^{2}-a t_{2}^{2}-b \max \left\{t_{3} t_{4}, t_{5} t_{6}\right\}$, where $a, b \in \mathbb{R}$ and $a+b<1$.

ExAMPLE 3.8. $F\left(t_{1}, \ldots, t_{6}\right)=t_{1}-a t_{2}-b \sqrt{t_{3} t_{4}}-c \sqrt{t_{5} t_{6}}$, where $a, b, c \in \mathbb{R}$ and $a+c<1$. 
The purpose of this paper is to prove a general fixed point theorem for mappings involving almost altering distance and a new type of common limit range property in $G_{p}$-metric spaces. In the last part of the paper, some fixed point results for mappings satisfying contractive conditions of integral type and for $\varphi$-contractive mappings are obtained.

\section{Main results}

LeMma 4.1 ([2]). Let $f, g$ be two weakly compatible self mappings of a nonempty set $X$. If $f$ and $g$ have a unique point of coincidence $w=f x=g x$ for some $x \in X$, then $w$ is the unique common fixed point of $f$ and $g$.

TheOREM 4.1. Let $A, B, S$ and $T$ be self mappings of a $G_{p}$-metric space $\left(X, G_{p}\right)$ satisfying

$$
F\left(\begin{array}{l}
\psi\left(G_{p}(A x, B y, B y)\right), \psi\left(G_{p}(S x, T y, T y)\right), \psi\left(G_{p}(S x, S x, A x)\right) \\
\psi\left(G_{p}(T y, B y, B y)\right), \psi\left(G_{p}(S x, B y, B y)\right), \psi\left(G_{p}(A x, T y, T y)\right)
\end{array}\right) \leq 0
$$

for all $x, y \in X$, where $F \in \mathcal{F}_{G_{p}}$ and $\psi$ is an almost altering distance.

If $(A, S)$ and $T$ satisfy $C L R_{(A, S) T}$-property, then

1) $\mathcal{C}(A, S) \neq \emptyset$,

2) $\mathcal{C}(B, T) \neq \emptyset$.

Moreover, if $(A, S)$ and $(B, T)$ are weakly compatible, then $A, B, S$ and $T$ have a unique common fixed point $z$ and $G_{p}(z, z, z)=0$.

Proof. Since $(A, S)$ and $T$ satisfy $C L R_{(A, S) T}$-property, then there exists a sequence $\left\{x_{n}\right\}$ in $X$ such that $\lim _{n \rightarrow \infty} A x_{n}=\lim _{n \rightarrow \infty} S x_{n}=z$ with $G_{p}(z, z, z)=0$ and $z \in S(X) \cap T(X)$.

Since $z \in T(X)$, there exists $u \in X$ such that $z=T u$. By (4.1) we obtain

$$
F\left(\begin{array}{c}
\psi\left(G_{p}\left(A x_{n}, B u, B u\right)\right), \psi\left(G_{p}\left(S x_{n}, T u, T u\right)\right), \psi\left(G_{p}\left(S x_{n}, S x_{n}, A x_{n}\right)\right), \\
\psi\left(G_{p}(T u, B u, B u)\right), \psi\left(G_{p}\left(S x_{n}, B u, B u\right)\right), \psi\left(G_{p}\left(A x_{n}, T u, T u\right)\right)
\end{array}\right) \leq 0 .
$$

Since $G_{p}\left(A x_{n}, S x_{n}, S x_{n}\right) \leq G_{p}\left(A x_{n}, z, z\right)+G_{p}\left(z, S x_{n}, S x_{n}\right)$, by Lemma 2.4

$$
\lim _{n \rightarrow \infty} G_{p}\left(A x_{n}, S x_{n}, S x_{n}\right) \leq G_{p}(z, z, z)+G_{p}(z, z, z)=0 .
$$


Letting $n$ tend to infinity in 4.2 we obtain

$$
F\left(\begin{array}{c}
\psi\left(G_{p}(z, B u, B u)\right), 0,0 \\
\psi\left(G_{p}(z, B u, B u)\right), \psi\left(G_{p}(z, B u, B u)\right), 0
\end{array}\right) \leq 0,
$$

which contradicts $\left(F_{2}\right)$, if $G_{p}(z, B u, B u)>0$. Hence, $G_{p}(z, B u, B u)=0$ and by Lemma $2.2(1), z=B u=T u$. Therefore, $\mathcal{C}(B, T) \neq \emptyset$ and $G_{p}(z, z, z)=0$.

Since $z \in S(X)$, there exists $v \in X$ such that $z=S v$.

By (4.1) we obtain

$$
\begin{gathered}
F\left(\begin{array}{c}
\psi\left(G_{p}(A v, B u, B u)\right), \psi\left(G_{p}(S v, T u, T u)\right), \psi\left(G_{p}(S v, S v, A v)\right), \\
\psi\left(G_{p}(T u, B u, B u)\right), \psi\left(G_{p}(S v, B u, B u)\right), \psi\left(G_{p}(A v, T u, T u)\right)
\end{array}\right) \leq 0 \\
F\left(\begin{array}{c}
\psi\left(G_{p}(A v, z, z)\right), 0, \psi\left(G_{p}(A v, z, z)\right), \\
0,0, \psi\left(G_{p}(A v, z, z)\right)
\end{array}\right) \leq 0
\end{gathered}
$$

which contradicts $\left(F_{1}\right)$, if $G_{p}(A v, z, z)>0$. Hence, $G_{p}(A v, z, z)=0$ and by Lemma 2.2 (1), $z=A v=S v$. Therefore, $z=A v=S v=T u=B u$ and $z$ is a point of coincidence of $A$ and $S$ and of $B$ and $T$ with $G_{p}(z, z, z)=0$.

We prove that $z$ is the unique point of coincidence of $A$ and $S$ and of $B$ and $T$.

Suppose that there exists another point of coincidence of $A$ and $S, t=$ $A w=S w$. Then, by 4.1 we obtain

$$
\begin{gathered}
F\left(\begin{array}{c}
\psi\left(G_{p}(A w, B u, B u)\right), \psi\left(G_{p}(S w, T u, T u)\right), \psi\left(G_{p}(S w, S w, A w)\right), \\
\psi\left(G_{p}(T u, B u, B u)\right), \psi\left(G_{p}(S w, B u, B u)\right), \psi\left(G_{p}(A w, T u, T u)\right)
\end{array}\right) \leq 0 \\
F\left(\begin{array}{c}
\psi\left(G_{p}(S w, T u, T u)\right), \psi\left(G_{p}(S w, T u, T u)\right), \psi\left(G_{p}(S w, S w, S w)\right), \\
0, \psi\left(G_{p}(S w, T u, T u)\right), \psi\left(G_{p}(S w, T u, T u)\right)
\end{array}\right) \leq 0 \\
F\left(\begin{array}{c}
\psi\left(G_{p}(S w, T u, T u)\right), \psi\left(G_{p}(S w, T u, T u)\right), 0, \\
0, \psi\left(G_{p}(S w, T u, T u)\right), \psi\left(G_{p}(S w, T u, T u)\right)
\end{array}\right) \leq 0
\end{gathered}
$$

which contradicts $\left(F_{3}\right)$, if $G_{p}(S w, T u, T u)>0$. Hence, $G_{p}(S w, T u, T u)=0$ which by Lemma 2.2 (1) implies that $S w=T u=z$. Hence, $t=z$ and $z$ is the unique point of coincidence of $A$ and $S$.

Similarly, by 4.1), $\left(F_{1}\right)$ and $\left(F_{2}\right)$, we obtain that $z$ is the unique point of coincidence of $B$ and $T$.

Hence, $z$ is the unique point of coincidence of $(A, S)$ and $(B, T)$.

Moreover, if $(A, S)$ and $(B, T)$ are weakly compatible, by Lemma $4.1, z$ is the unique common fixed point of $A, B, S$ and $T$ and $G_{p}(z, z, z)=0$.

If $\psi(t)=t$, we obtain 
TheOrem 4.2. Let $A, B, S$ and $T$ be self mappings of a $G_{p}$-metric space $\left(X, G_{p}\right)$ satisfying

$$
F\left(\begin{array}{c}
G_{p}(A x, B y, B y), G_{p}(S x, T y, T y), G_{p}(S x, S x, A x), \\
G_{p}(T y, B y, B y), G_{p}(S x, B y, B y), G_{p}(A x, T y, T y)
\end{array}\right) \leq 0
$$

for all $x, y \in X$, where $F \in \mathcal{F}_{G_{p}}$.

If $(A, S)$ and $T$ satisfy $C L R_{(A, S) T}$-property, then

1) $\mathcal{C}(A, S) \neq \emptyset$,

2) $\mathcal{C}(B, T) \neq \emptyset$.

Moreover, if $(A, S)$ and $(B, T)$ are weakly compatible, then $A, B, S$ and $T$ have a unique common fixed point $z$ and $G_{p}(z, z, z)=0$.

EXAmPle 4.1. Let $X=[0,1]$ and $G_{p}(x, y, z)=\max \{x, y, z\}$. Then $\left(X, G_{p}\right)$ is a $G_{p}$-metric space.

Consider the following mappings:

$$
A x=0, S x=\frac{x}{x+1}, B x=\frac{x}{3}, T x=x .
$$

Then $S(X)=\left[0, \frac{1}{2}\right], T(X)=[0,1]$ and $S(X) \cap T(X)=\left[0, \frac{1}{2}\right]$.

Let $\left\{x_{n}\right\}$ be a sequence in $X$ such that $\lim _{n \rightarrow \infty} x_{n}=0$. Then,

$$
\lim _{n \rightarrow \infty} A x_{n}=\lim _{n \rightarrow \infty} S x_{n}=0=z \in S(X) \cap T(X) .
$$

Hence, $(A, S)$ and $T$ satisfy $C L R_{(A, S) T}$-property with $G_{p}(0,0,0)=0$.

$A x=S x$ implies $\mathcal{C}(A, S)=\{0\}$ and $B x=T x$ implies $\mathcal{C}(B, T)=\{0\}$. Moreover, $A S 0=S A 0=0$ and $B T 0=T B 0=0$. Hence, $(A, S)$ and $(B, T)$ are weakly compatible. On the other hand,

$$
G_{p}(A x, B y, B y)=\frac{y}{3} \text { and } G_{p}(T y, B y, B y)=y .
$$

Hence, $G_{p}(A x, B y, B y) \leq k y$, where $k \in\left[\frac{1}{3}, 1\right)$, which implies

$$
\begin{aligned}
G_{p}(A x, B y, B y) \leq & k \max \left\{G_{p}(S x, T y, T y), G_{p}(S x, S x, A x),\right. \\
& \left.G_{p}(T y, B y, B y), G_{p}(S x, B y, B y), G_{p}(A x, T y, T y)\right\},
\end{aligned}
$$

where $k \in\left[\frac{1}{3}, 1\right)$. By Theorem 4.1 and Example 3.2, $A, B, S$ and $T$ have a unique common fixed point $z=0$ and $G_{p}(z, z, z)=0$. 


\section{Applications}

\subsection{Fixed points for mappings satisfying contractive conditions of integral type in $G_{p}$-metric spaces}

In [8], Branciari established the following theorem, which opened the way to the study of fixed points for mappings satisfying a contractive condition of integral type.

TheOREM $5.1([8])$. Let $(X, d)$ be a complete metric space, $c \in(0,1)$ and $f: X \rightarrow X$ be a mapping such that for all $x, y \in X$

$$
\int_{0}^{d(f x, f y)} h(t) d t \leq c \int_{0}^{d(x, y)} h(t) d t
$$

where $h:[0, \infty) \rightarrow[0, \infty)$ is a Lebesgue measurable mapping, integrable on each compact subset of $[0, \infty)$, such that $\int_{0}^{\varepsilon} h(t) d t>0$ for $\varepsilon>0$. Then $f$ has a unique fixed point $z \in X$ and $z=\lim _{n \rightarrow \infty} f^{n} x$ for all $x \in X$.

Theorem 5.1 has been extended to a pair of compatible mappings in [25].

Some fixed point results for mappings satisfying contractive conditions of integral type have been obtained in [42, 46, 47, 54] and in other papers.

Lemma $5.1([47)$. Let $h:[0, \infty) \rightarrow[0, \infty)$ be as in Theorem 5.1. Then $\psi(x)=\int_{0}^{x} h(t) d t$ is an almost altering distance.

ProOF. It follows by [47, Lemma 2.5].

THEOREM 5.2. Let $A, B, S$ and $T$ be self mappings of a $G_{p}$-metric space $\left(X, G_{p}\right)$ such that

$$
F\left(\begin{array}{l}
\int_{0}^{G_{p}(A x, B y, B y)} h(t) d t, \int_{0}^{G_{p}(S x, T y, T y)} h(t) d t, \int_{0}^{G_{p}(S x, S x, A x)} h(t) d t, \\
\int_{0}^{G_{p}(T y, B y, B y)} h(t) d t, \int_{0}^{G_{p}(S x, B y, B y)} h(t) d t, \int_{0}^{G_{p}(A x, T y, T y)} h(t) d t
\end{array}\right) \leq 0
$$

for all $x, y \in X$, where $F \in \mathcal{F}_{G_{p}}$ and $h(t)$ is as in Theorem 5.1.

If $(A, S)$ and $T$ satisfy $C L R_{(A, S) T \text {-property, then }}$

1) $\mathcal{C}(A, S) \neq \emptyset$

2) $\mathcal{C}(B, T) \neq \emptyset$.

Moreover, if $(A, S)$ and $(B, T)$ are weakly compatible, then $A, B, S$ and $T$ have a unique common fixed point $z$ and $G_{p}(z, z, z)=0$. 
Proof. Taking $\psi(x)=\int_{0}^{x} h(t) d t$ we obtain

$$
\begin{aligned}
\psi\left(G_{p}(A x, B y, B y)\right) & =\int_{0}^{G_{p}(A x, B y, B y)} h(t) d t, \\
\psi\left(G_{p}(S x, T y, T y)\right) & =\int_{0}^{G_{p}(S x, T y, T y)} h(t) d t, \\
\psi\left(G_{p}(S x, S x, A x)\right) & =\int_{0}^{G_{p}(S x, S x, A x)} h(t) d t, \\
\psi\left(G_{p}(T y, B y, B y)\right) & =\int_{0}^{G_{p}(T y, B y, B y)} h(t) d t, \\
\psi\left(G_{p}(S x, B y, B y)\right) & =\int_{0}^{G_{p}(S x, B y, B y)} h(t) d t, \\
\psi\left(G_{p}(A x, T y, T y)\right) & =\int_{0}^{G_{p}(A x, T y, T y)} h(t) d t .
\end{aligned}
$$

Then, by (5.1) we obtain

$$
F\left(\begin{array}{l}
\psi\left(G_{p}(A x, B y, B y)\right), \psi\left(G_{p}(S x, T y, T y)\right), \psi\left(G_{p}(S x, S x, A x)\right), \\
\psi\left(G_{p}(T y, B y, B y)\right), \psi\left(G_{p}(S x, B y, B y)\right), \psi\left(G_{p}(A x, T y, T y)\right)
\end{array}\right) \leq 0,
$$

that is inequality (4.1). Moreover, by Lemma 5.1, $\psi$ is an almost altering distance.

Hence, the conditions of Theorem 4.1 are satisfied and the conclusions of Theorem 5.2 follows by Theorem 4.1 .

By Theorem 5.2 and Example 3.2 we obtain the following.

ThEOREM 5.3. Let $A, B, S$ and $T$ be self mappings of a $G_{p}$-metric space $\left(X, G_{p}\right)$ such that

$$
\begin{gathered}
\int_{0}^{G_{p}(A x, B y, B y)} h(t) d t \leq k \max \left\{\int_{0}^{G_{p}(S x, T y, T y)} h(t) d t, \int_{0}^{G_{p}(S x, S x, A x)} h(t) d t,\right. \\
\left.\int_{0}^{G_{p}(T y, B y, B y)} h(t) d t, \int_{0}^{G_{p}(S x, B y, B y)} h(t) d t, \int_{0}^{G_{p}(A x, T y, T y)} h(t) d t\right\}
\end{gathered}
$$

for all $x, y \in X$, where $k \in[0,1)$ and $h(t)$ is as in Theorem 5.1.

If $(A, S)$ and $T$ satisfy $C L R_{(A, S) T}$-property, then

1) $\mathcal{C}(A, S) \neq \emptyset$,

2) $\mathcal{C}(B, T) \neq \emptyset$. 
Moreover, if $(A, S)$ and $(B, T)$ are weakly compatible, then $A, B, S$ and $T$ have a unique common fixed point $z$ and $G_{p}(z, z, z)=0$.

ExAmple 5.1. Let $X=[0, \infty)$ and $G_{p}(x, y, z)=\max \{x, y, z\}$. Then $\left(X, G_{p}\right)$ is a $G_{p}$-metric space.

Consider the following mappings:

$$
A x=\frac{x}{2}, S x=2 x, B x=0, T x=x .
$$

Then $S(X)=[0, \infty), T(X)=[0, \infty)$ and $S(X) \cap T(X)=[0, \infty)$.

Let $\left\{x_{n}\right\}$ be a sequence in $X$ such that $\lim _{n \rightarrow \infty} x_{n}=0$. Then

$$
\lim _{n \rightarrow \infty} S x_{n}=\lim _{n \rightarrow \infty} A x_{n}=0=z \in S(X) \cap T(X)
$$

and $G_{p}(z, z, z)=G(0,0,0)=0$. Hence, $(A, S)$ and $T$ satisfy $C L R_{(A, S) T^{-}}$ -property.

$A x=S x$ implies $\mathcal{C}(A, S)=\{0\}$ and $B x=T x$ implies $\mathcal{C}(B, T)=\{0\}$. Moreover, $A S 0=S A 0=0$ and $B T 0=T B 0=0$. Hence, $(A, S)$ and $(B, T)$ are weakly compatible. On the other hand,

$$
G_{p}(A x, B y, B y)=A x=\frac{x}{2} \text { and } G_{p}(S x, S x, A x)=2 x .
$$

Moreover,

$$
\int_{0}^{x / 2} t d t \leq k \int_{0}^{2 x} t d t
$$

for $k \geq \frac{1}{16}$. Thus, for $h(t)=t$ we obtain

$$
\int_{0}^{G_{p}(A x, B y, B y)} h(t) d t \leq k \int_{0}^{G_{p}(S x, S x, A x)} h(t) d t,
$$

where $\frac{1}{16} \leq k<1$. Hence,

$$
\begin{array}{r}
\int_{0}^{G_{p}(A x, B y, B y)} h(t) d t \leq k \max \left\{\int_{0}^{G_{p}(S x, T y, T y)} h(t) d t, \int_{0}^{G_{p}(S x, S x, A x)} h(t) d t\right. \\
\left.\int_{0}^{G_{p}(T y, B y, B y)} h(t) d t, \int_{0}^{G_{p}(S x, B y, B y)} h(t) d t, \int_{0}^{G_{p}(A x, T y, T y)} h(t) d t\right\}
\end{array}
$$

where $k \in\left[\frac{1}{16}, 1\right)$. By Theorem 5.3, $A, B, S$ and $T$ have a unique common fixed point $z=0$. 
Remark 5.1. By Theorem 5.2 and Examples $3.1,3.3,3.8$ we obtain new particular results.

\subsection{Fixed points for mappings satisfying $\varphi$-contractive conditions in $G_{p}$-metric spaces}

As in [27], let $\Phi$ be the set of real continuous nondecreasing functions $\varphi:[0, \infty) \rightarrow[0, \infty)$ with $\lim _{n \rightarrow \infty} \varphi^{n}(t)=0$.

If $\varphi \in \Phi$, then

(1) $\varphi(t)<t$ for all $t \in(0, \infty)$,

(2) $\varphi(0)=0$.

The following functions $F: \mathbb{R}_{+}^{6} \rightarrow \mathbb{R}_{+}$satisfy conditions $\left(F_{1}\right),\left(F_{2}\right),\left(F_{3}\right)$.

ExAMPLE 5.2. $F\left(t_{1}, \ldots, t_{6}\right)=t_{1}-\varphi\left(\max \left\{t_{2}, t_{3}, \ldots, t_{6}\right\}\right)$.

EXAMPle 5.3. $F\left(t_{1}, \ldots, t_{6}\right)=t_{1}-\varphi\left(\max \left\{t_{2}, t_{3}, t_{4}, \frac{t_{5}+t_{6}}{2}\right\}\right)$.

EXAMPLE 5.4. $F\left(t_{1}, \ldots, t_{6}\right)=t_{1}-\varphi\left(\max \left\{t_{2}, \frac{t_{3}+t_{4}}{2}, \frac{t_{5}+t_{6}}{2}\right\}\right)$.

EXAMPLE 5.5. $F\left(t_{1}, \ldots, t_{6}\right)=t_{1}-\varphi\left(\max \left\{t_{2}, t_{3}, t_{4}, \sqrt{t_{5} t_{6}}\right\}\right)$.

EXAmPle 5.6. $F\left(t_{1}, \ldots, t_{6}\right)=t_{1}-\varphi\left(a t_{2}+b t_{3}+c t_{4}+d t_{5}+e t_{6}\right)$, where $a, b, c, d, e \geq 0$ and $a+b+c+d+e<1$.

EXAMPle 5.7. $F\left(t_{1}, \ldots, t_{6}\right)=t_{1}-\varphi\left(a t_{2}+b \max \left\{t_{3}, t_{4}\right\}+c \max \left\{\frac{t_{3}+t_{4}}{2}\right.\right.$, $\left.\left.\frac{t_{5}+t_{6}}{2}\right\}\right)$, where $a, b, c \geq 0$ and $a+b+c<1$.

By Theorem 4.1 and Example 5.3 we obtain

TheOrem 5.4. Let $A, B, S$ and $T$ be self mappings of a $G_{p}$-metric space $\left(X, G_{p}\right)$ such that

$$
\begin{array}{r}
\psi\left(G_{p}(A x, B y, B y)\right) \leq \varphi\left(\operatorname { m a x } \left\{\psi\left(G_{p}(S x, T y, T y)\right), \psi\left(G_{p}(S x, S x, A x)\right),\right.\right. \\
\left.\left.\psi\left(G_{p}(T y, B y, B y)\right), \frac{\psi\left(G_{p}(S x, B y, B y)\right)+\psi\left(G_{p}(A x, T y, T y)\right)}{2}\right\}\right)
\end{array}
$$

for all $x, y \in X$, where $\varphi \in \Phi$ and $\psi$ is an almost altering distance.

If $(A, S)$ and $T$ satisfy $C L R_{(A, S) T}$-property, then

1) $\mathcal{C}(A, S) \neq \emptyset$,

2) $\mathcal{C}(B, T) \neq \emptyset$. 
Moreover, if $(A, S)$ and $(B, T)$ are weakly compatible, then $A, B, S$ and $T$ have a unique common fixed point $z$ and $G_{p}(z, z, z)=0$.

Example 5.8. Let $\left(X, G_{p}\right), A, S, B$ and $T$ be as in Example 5.1. Put $\varphi(t)=\frac{t}{2}$. Obviously, $\varphi \in \Phi$.

It follows from Example 5.1 that $(A, S)$ and $T$ satisfy $C L R_{(A, S) T^{-}}$property, $(A, S)$ and $(B, T)$ are weakly compatible and

$$
G_{p}(A x, B y, B y)=A x=\frac{x}{2} \text { and } G_{p}(S x, S x, A x)=2 x,
$$

which implies

$$
\begin{aligned}
G_{p}(A x, B y, B y) \leq & \frac{1}{2} G_{p}(S x, S x, A x) \\
\leq & \frac{1}{2} \max \left\{G_{p}(S x, T y, T y), G_{p}(S x, S x, A x),\right. \\
& \left.G_{p}(T y, B y, B y), \frac{G_{p}(S x, B y, B y)+G_{p}(A x, T y, T y)}{2}\right\} \\
= & \varphi\left(\operatorname { m a x } \left\{G_{p}(S x, T y, T y), G_{p}(S x, S x, A x),\right.\right. \\
& \left.\left.\quad G_{p}(T y, B y, B y), \frac{G_{p}(S x, B y, B y)+G_{p}(A x, T y, T y)}{2}\right\}\right) .
\end{aligned}
$$

By Theorem 5.4 $A, B, S$ and $T$ have a unique common fixed point $z=0$.

By Theorem 5.2 and Example 5.3 we obtain the following.

THEOREM 5.5. Let $A, B, S$ and $T$ be self mappings of a $G_{p}$-metric space $\left(X, G_{p}\right)$ such that

$$
\begin{gathered}
\int_{0}^{G_{p}(A x, B y, B y)} h(t) d t \leq \varphi\left(\operatorname { m a x } \left\{\int_{0}^{G_{p}(S x, T y, T y)} h(t) d t, \int_{0}^{G_{p}(S x, S x, A x)} h(t) d t,\right.\right. \\
\left.\left.\int_{0}^{G_{p}(T y, B y, B y)} h(t) d t, \frac{\int_{0}^{G_{p}(S x, B y, B y)} h(t) d t+\int_{0}^{G_{p}(A x, T y, T y)} h(t) d t}{2}\right\}\right)
\end{gathered}
$$

for all $x, y \in X$, where $h(t)$ is as in Theorem 5.1.

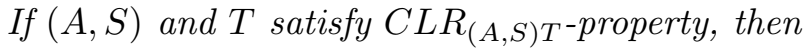

1) $\mathcal{C}(A, S) \neq \emptyset$,

2) $\mathcal{C}(B, T) \neq \emptyset$.

Moreover, if $(A, S)$ and $(B, T)$ are weakly compatible, then $A, B, S$ and $T$ have a unique common fixed point $z$ and $G_{p}(z, z, z)=0$. 
Remark 5.2. By Theorem 5.2 and Examples 5.2, 5.4 5.7 we obtain new particular results.

Acknowledgement. The authors thank the anonymous referee for his/ her careful reading of the manuscript and his/her valuable remarks that improved the final version of the paper.

\section{References}

[1] Aamri M., El Moutawakil D., Some new common fixed point theorems under strict contractive conditions, J. Math. Anal. Appl. 270 (2002), no. 1, 181-188.

[2] Abbas M., Rhoades B.E., Common fixed point results for noncommuting mappings without continuity in generalized metric spaces, Appl. Math. Comput. 215 (2009), no. 1, 262-269.

[3] Ahmadi Zand M.R., Dehghan Nezhad A., A generalization of partial metric spaces, J. Contemp. Appl. Math. 1 (2011), no. 1, 86-93.

[4] Ali J., Imdad M., An implicit function implies several contraction conditions, Sarajevo J. Math. 4(17) (2008), no. 2, 269-285.

[5] Aydi H., Karapınar E., Salimi P., Some fixed point results in GP-metric spaces, J. Appl. Math. 2012, Art. ID 891713, 16 pp.

[6] Barakat M.A., Zidan A.M., A common fixed point theorem for weak contractive maps in $G_{p}$-metric spaces, J. Egyptian. Math. Soc. 23 (2015), no. 2, 309-314.

[7] Bilgili N., Karapınar E., Salimi P., Fixed point theorems for generalized contractions on GP-metric spaces, J. Inequal. Appl. 2013, 2013:39, 13 pp.

[8] Branciari A., A fixed point theorem for mappings satisfying a general contractive condition of integral type, Int. J. Math. Math. Sci. 29 (2002), no. 9, 531-536.

[9] Chi K.P., Karapinar E., Thanh T.D., A generalized contraction principle in partial metric spaces, Math. Comput. Modelling 55 (2012), no. 5-6, 1673-1681.

[10] Ćirić L., Samet B., Aydi H., Vetro C., Common fixed points of generalized contractions on partial metric spaces and an application, Appl. Math. Comput. 218 (2011), no. 6, 2398-2406.

[11] Dhage B.C., Generalised metric spaces and mappings with fixed point, Bull. Calcutta Math. Soc. 84 (1992), no. 4, 329-336.

[12] Dhage B.C., Generalized metric spaces and topological structure. I, An. Ştiinţ. Univ. Al. I. Cuza Iaşi Mat. (N.S.) 46 (2000), no. 1, 3-24 (2001).

[13] Gülyaz S., Karapınar E., A coupled fixed point result in partially ordered partial metric spaces through implicit function, Hacet. J. Math. Stat. 42 (2013), no. 4, 347-357.

[14] Gülyaz S., Karapınar E., Yüce İ.S., A coupled coincidence point theorem in partially ordered metric spaces with an implicit relation, Fixed Point Theory Appl. 2013, 2013:38, $11 \mathrm{pp}$.

[15] Imdad M., Chauhan S., Employing common limit range property to prove unified metrical common fixed point theorems, Int. J. Anal. 2013, Art. ID 763261, 10 pp.

[16] Imdad M., Chauhan S., Kadelburg Z., Fixed point theorem for mappings with common limit range property satisfying generalized $(\psi, \phi)$-weak contractive conditions, Math. Sci. (Springer) 7 (2013), Art. 16, 8 pp.

[17] Imdad M., Pant B.D., Chauhan S., Fixed point theorems in Menger spaces using $\left(C L R_{(S T)}\right)$ property and applications, J. Nonlinear Anal. Optim. 3 (2012), no. 2, 225-237. 
[18] Imdad M., Sharma A., Chauhan S., Unifying a multitude of common fixed point theorems in symmetric spaces, Filomat 28 (2014), no. 6, 1113-1132.

[19] Jungck G., Compatible mappings and common fixed points, Internat. J. Math. Math. Sci. 9 (1986), no. 4, 771-779.

[20] Jungck G., Common fixed points for noncontinuous nonself maps on nonmetric spaces, Far East J. Math. Sci. 4 (1996), no. 2, 199-215.

[21] Kadelburg Z., Nashine H.K., Radenović S., Fixed point results under various contractive conditions in partial metric spaces, Rev. R. Acad. Cienc. Exactas Fís. Nat. Ser. A Math. RACSAM 107 (2013), no. 2, 241-256.

[22] Karapınar E., Yüksel U., Some common fixed point theorems in partial metric spaces, J. Appl. Math. 2011, Art. ID 263621, 16 pp.

[23] Karapınar E., Patel D.K., Imdad M., Gopal D., Some nonunique common fixed point theorems in symmetric spaces through $C L R_{(S, T)}$ property, Int. J. Math. Math. Sci. (2013), Art. ID 753965, 8 pp.

[24] Khan M.S., Swaleh M., Sessa S., Fixed point theorems by altering distances between the points, Bull. Austral. Math. Soc. 30 (1984), no. 1, 1-9.

[25] Kumar S., Chugh R., Kumar R., Fixed point theorem for compatible mappings satisfying a contractive condition of integral type, Soochow J. Math. 33 (2007), no. 2, 181-185.

[26] Liu Y., Wu J., Li Z., Common fixed points of single-valued and multivalued maps, Int. J. Math. Math. Sci. 2005, no. 19, 3045-3055.

[27] Matkowski J., Fixed point theorems for mappings with a contractive iterate at a point, Proc. Amer. Math. Soc. 62 (1977), no. 2, 344-348.

[28] Matthews S.G., Partial metric topology, in: Andima S. et al. (eds.), Papers on General Topology and Applications: Eighth Summer Conference at Queens College, New York Acad. Sci. 728, New York Academy of Sciences, New York, 1994, pp. 183-197.

[29] Mustafa Z., Khandagji M., Shatanawi W., Fixed point results on complete G-metric spaces, Studia Sci. Math. Hungar. 48 (2011), no. 3, 304-319.

[30] Mustafa Z., Obiedat H., A fixed point theorem of Reich in G-metric spaces, Cubo 12 (2010), no. 1, 83-93.

[31] Mustafa Z., Obiedat H., Awawdeh F., Some fixed point theorem for mapping on complete G-metric spaces, Fixed Point Theory Appl. 2008, Art. ID 189870, 12 pp.

[32] Mustafa Z., Sims B., Some remarks concerning D-metric spaces, in: Falset J.G. et al. (eds.), Proceedings of the International Conference on Fixed Point Theory and Applications (Valencia, Spain, 2003), Yokohama Publ., Yokohama, 2004, pp. 189-198.

[33] Mustafa Z., Sims B., A new approach to generalized metric spaces, J. Nonlinear Convex Anal. 7 (2006), no. 2, 287-297.

[34] Mustafa Z., Sims B., Fixed point theorems for contractive mappings in complete Gmetric spaces, Fixed Point Theory Appl. 2009, Art. ID 917175, 10 pp.

[35] Pant R.P., Common fixed points of noncommuting mappings, J. Math. Anal. Appl. 188 (1994), no. 2, 436-440.

[36] Pant R.P., Common fixed points of four mappings, Bull. Calcutta Math. Soc. 90 (1998), no. 4, 281-286.

[37] Pant R.P., Common fixed point theorems for contractive maps, J. Math. Anal. Appl. 226 (1998), no. 1, 251-258.

[38] Pant R.P., R-weak commutativity and common fixed points of noncompatible maps, Ganita 49 (1998), no. 1, 19-27.

[39] Pant R.P., R-weak commutativity and common fixed points, Soochow J. Math. 25 (1999), no. 1, 37-42.

[40] Parvaneh V., Roshan J.R., Kadelburg Z., On generalized weakly GP-contractive mappings in ordered GP-metric spaces, Gulf J. Math. 1 (2013), no. 1, 78-97.

[41] Pathak H.K., Rodríguez-López R., Verma R.K., A common fixed point theorem using implicit relation and property (E.A) in metric spaces, Filomat 21 (2007), no. 2, 211-234. 
[42] Pathak H.K., Rodríguez-López R., Verma R.K., A common fixed point theorem of integral type using implicit relation, Nonlinear Funct. Anal. Appl. 15 (2010), no. 1, $1-12$.

[43] Popa V., Fixed point theorems for implicit contractive mappings, Stud. Cercet. Ştiinţ. Ser. Mat. Univ. Bacău 7 (1997), 127-133.

[44] Popa V., Some fixed point theorems for compatible mappings satisfying an implicit relation, Demonstratio Math. 32 (1999), no. 1, 157-163.

[45] Popa V., Fixed point theorems for two pairs of mappings satisfying a new type of common limit range property, Filomat 31 (2017), no. 11, 3181-3192.

[46] Popa V., Mocanu M., A new viewpoint in the study of fixed points for mappings satisfying a contractive condition of integral type, Bull. Inst. Politeh. Iaşi Secţ. Mat. Mec. Teor. Fiz. 53(57) (2007), no. 5, 269-286.

[47] Popa V., Mocanu M., Altering distance and common fixed points under implicit relations, Hacet. J. Math. Stat. 38 (2009), no. 3, 329-337.

[48] Popa V., Patriciu A.-M., A general fixed point theorem for mappings satisfying an $\phi$-implicit relation in complete G-metric spaces, Gazi Univ. J. Sci. 25 (2012), no. 2, 403-408.

[49] Popa V., Patriciu A.-M., A general fixed point theorem for pairs of weakly compatible mappings in G-metric spaces, J. Nonlinear Sci. Appl. 5 (2012), no. 2, 151-160.

[50] Popa V., Patriciu A.-M., Two general fixed point theorems for pairs of weakly compatible mappings in G-metric spaces, Novi Sad J. Math. 42 (2012), no. 2, 49-60.

[51] Popa V., Patriciu A.-M., A general fixed point theorem for a pair of self mappings with common limit range property in $G$-metric spaces, Facta Univ. Ser. Math. Inform. 29 (2014), no. 4, 351-370.

[52] Popa V., Patriciu A.-M., Two general fixed point theorems for a sequence of mappings satisfying implicit relations in $G_{p}$-metric spaces, Appl. Gen. Topol. 16 (2015), no. 2, 225-231.

[53] Popa V., Patriciu A.-M., Well posedness of fixed point problem for mappings satisfying an implicit relation in $G_{p}$-metric spaces, Math. Sci. Appl. E-Notes 3 (2015), no. 1, $108-117$.

[54] Rhoades B.E., Two fixed-point theorems for mappings satisfying a general contractive condition of integral type, Int. J. Math. Math. Sci. 2003, no. 63, 4007-4013.

[55] Sastry K.P.R., Babu G.V.R., Fixed point theorems in metric spaces by altering distances, Bull. Calcutta Math. Soc. 90 (1998), no. 3, 175-182.

[56] Sastry K.P.R., Babu G.V.R., Some fixed point theorems by altering distances between the points, Indian J. Pure Appl. Math. 30 (1999), no. 6, 641-647.

[57] Shatanawi W., Fixed point theory for contractive mappings satisfying $\Phi$-maps in $G$ metric spaces, Fixed Point Theory Appl. 2010, Art. ID 181650, 9 pp.

[58] Sintunavarat W., Kumam P., Common fixed point theorems for a pair of weakly compatible mappings in fuzzy metric spaces, J. Appl. Math. 2011, Art. ID 637958, 14 pp.

[59] Vetro C., Vetro F., Common fixed points of mappings satisfying implicit relations in partial metric spaces, J. Nonlinear Sci. Appl. 6 (2013), no. 3, 152-161.

"VAsile Alecsandri"

UNIVERSITY OF BACĂU

157 Calea MărăşEşTi

BACĂU, 600115

Romania

e-mail:vpopa@ub.ro
"Dunărea de Jos" University of Galaţi

FaCulty of Sciences and Environment

Department of Mathematics and Computer Sciences 111 Domnească Street

Galaţi, 800201

Romania

e-mail: Alina.Patriciu@ugal.ro 